\title{
Well, Slap My Thigh: Expression of Surprise Facilitates Memory of Surprising Material
}

\author{
Michal Parzuchowski and Aleksandra Szymkow-Sudziarska \\ Warsaw School of Social Psychology, Faculty in Sopot
}

\begin{abstract}
Two studies examined the general prediction that one's emotional expression should facilitate memory for material that matches the expression. The authors focused on specific facial expressions of surprise. In the first study, participants who were mimicking a surprised expression showed better recall for the surprising words and worse recall for neutral words, relative to those who were mimicking a neutral expression. Study 2 replicated the results of Study 1, showing that participants who mimicked a surprised expression recalled more words spoken in a surprising manner compared with those that sounded neutral or sad. Conversely, participants who mimicked sad facial expressions showed greater recall for sad than neutral or surprising words. The results provide evidence of the importance of matching the emotional valence of the recall content to the facial expression of the recaller during the memorization period.
\end{abstract}

Keywords: surprise, embodiment, memory

We interact with the world through our brains and bodies, which themselves interact with each other. This view of cognition implies that cognitive representations and operations are fundamentally grounded in their physical context, which means that cognition relies on the brain's modality-specific systems as well as physical bodily states (Niedenthal, Barsalou, Winkielman, Krauth-Gruber, $\&$ Ric, 2005). The embodied nature of cognition has been demonstrated in various experiments (Niedenthal et al., 2005; Wilson, 2002). Bodily movements influence perception (Chandler \& Schwarz, 2006; Reed \& Farah, 1995), judgment (Berkowitz \& Troccoli, 1990; Neumann \& Strack, 2000), processing style (Friedman \& Förster, 2000), emotions (Stepper \& Strack, 1993), and as discussed in this article, memory (Förster \& Strack, 1997).

The embodiment approach to memory theorizes that "memory evolved in service of perception and action in a three-dimensional environment, and that memory is embodied to facilitate interaction with the environment" (Glenberg, 1997, p. 1). Thus, stored embodiments constitute the basic elements of knowledge (Niedenthal et al., 2005), and as Glenberg (1997) has shown, long-term memory as well as working and implicit memories are all tied to our bodies' experiences with the world. Manipulating the body into a state that is linked to relevant cognitive representations or emotions can make the body constrain other cognitive processing such as memory (Glenberg,

Michal Parzuchowski and Aleksandra Szymkow-Sudziarska, Warsaw School of Social Psychology, Faculty in Sopot, Sopot, Poland.

This work was partially supported by Warsaw School of Social Psychology Grant BW02/06. Both authors contributed equally and are listed in alphabetical order. We thank Jesse Chandler, Christine Chang-Schneider, Adam Kramer, Jesse Graham, Nicholas Fernandez, Megan O'Grady, and Kasia Dudulewicz for their insightful comments. We also thank students who helped in the realization of the experiments.

Correspondence concerning this article should be addressed to Aleksandra Szymkow-Sudziarska, Institute of Psychology, Warsaw School of Social Psychology, Faculty in Sopot, Ul. Polna 16/20, 81-745 Sopot, Poland. E-mail: aszymkow-sudziarska@swps.edu.pl
1997). For example, Förster and Strack (1997) demonstrated that motor behavior influenced the retrieval of attitude objects from longterm memory in an attitude-congruent manner. Participants who pulled upward on a table in front of them (i.e., symbolizing lifting the table; an approach behavior) recalled more names of celebrities they liked, whereas those who pushed down on the top of the table (an avoidance behavior) retrieved more names of people they disliked. In the same way, Riskind (1984) showed that standing upright and smiling speeds up the retrieval of pleasant memories but not unpleasant ones.

Our studies focused on the influence of facial expressions on memory. Specifically, we were interested in how matching the facial expression of a specific emotional state with the learned material facilitates recall. We have found few studies that emphasize the role of "matching" and its influence on embodied memory, although there are some hints that matching should be relevant. For example, time of retrieval is shorter when there is a match between the actual emotional state and the to-be-recalled material compared with the mismatch situation (Bower, 1981; Teasdale \& Fogarty, 1979). Also, memory deteriorates when participants block their natural facial expressions (Zajonc, Pietromonaco, \& Bargh, 1982). We attempted to take this research one step further: to show that when a facial expression does not match the emotional content of the material to be remembered, memory will also deteriorate. The vast majority of the studies on interaction between facial expressions and memory address a positive versus negative model of affective states. For example, Laird, Wagener, Halal, and Szegda (1982, Study 1) showed that happy content was more readily recalled when participants were induced to smile and angry material was better recalled when participants were induced to frown. We found only one example in which recall was assessed for cohesive emotional states, in which authors examined material that was angry, fearful, or sad with expressions of these respective types (Laird et al., 1982, Study 2). However, these studies are limited as they do not show whether the fit between content and expression is important during the learning process. In Study 1, 
participants wore the specific facial expressions only during recall, and in Study 2, they mimicked both during encoding and during the retrieval phase at the same time. Thus, we found these results confusing, as we cannot discern whether the effects were due to the match between facial expression and the material to be learned or due to the match of expressions and content at the time of recall. We wanted to examine whether the above fit is important not only during recall but also during the learning process (Bower, 1981).

In our studies, we focused on the specific facial expression of surprise. Our main hypothesis was that engaging in a facial expression of surprise facilitates the process of memorizing material that reflects surprise, whereas failing to match the facial expression with material to be learned results in inferior recall. In Study 1, we compared recall scores for material reflecting surprise to scores for neutral material, both learned while adopting either surprised or neutral facial expressions. The second study replicated Study 1, but added a sadness condition at both the material content level and the facial expression level.

\section{Study 1}

The aim of Study 1 was to examine how adopting the facial expression of surprise affects the process of memorizing surprising and neutral material. Participants were asked to mimic a neutral or surprised facial expression, as demonstrated by an actor in a picture. They were then asked to memorize and recall a list of surprising words (i.e., words that are not commonly used in everyday language) and neutral words (i.e., words frequently used in everyday language). We expected that surprised facial expression should precipitate and improve information processing, but only if the stimuli matched the embodied state (i.e., if the stimuli were surprising; Laird et al., 1982).

\section{Pilot Test}

To obtain photographic stimuli of surprised and neutral faces, 10 photographs of five students' faces depicting neutral and surprised looks were tested during an online study of 35 bloggers. Participants were asked to indicate the extent to which the faces expressed thoughtfulness, surprise, neutrality, fear, and anger on a scale from 1 (not at all) to 7 (very much). A set of 2 photos of a single female student (either neutral or surprised) was chosen that differed only on ratings for surprise and neutrality. Table 1 reveals that surprisingness of the surprised face $(M=5.33)$ was judged significantly higher than that of neutral face $(M=1.50)$, $t(17.01)=4.64, p<.001$, and the opposite was true for the neutral shot: Neutrality of the surprised face $(M=2.26)$ was significantly lower than that of neutral face $(M=6.80), t(33)=5.84, p<.001$.

To pretest words to memorize, two lists of five-lettered nouns differing in surprisingness of the content were prepared. One list comprised 20 surprising words (i.e., words very rarely used in Polish language, e.g., armor, veil), and the second comprised 20 neutral words (i.e., words frequently used in Polish language, e.g., house, door), which were picked from the Frequency Dictionary of Polish Language (Kurcz, Lewicki, Sambor, Szafran, \& Woronczak, 1990). Two independent judges rated the extent to which the words were positive, on a scale from -5 (very negative) to +5 (very positive), and typical, on a scale from -5 (very unusual) to +5 (very typical). Judges showed high agreement $(r=.73, p<$
Table 1

Ratings of Independent Judges of Two Photos Showing Actor's Neutral or Surprised Face: Pilot Study

\begin{tabular}{llllllllc}
\hline & \multicolumn{1}{c}{$\begin{array}{c}\text { Neutral face } \\
(n=20)\end{array}$} & \multicolumn{2}{c}{$\begin{array}{c}\text { Surprised face } \\
(n=15)\end{array}$} & & & \\
\cline { 2 - 5 } \multicolumn{1}{c}{$\begin{array}{c}\text { Judged } \\
\text { expression }\end{array}$} & $M$ & $S D$ & $M$ & $S D$ & $t$ & $d f$ & $p$ \\
\hline Surprise & 1.50 & 1.15 & 5.33 & 3.03 & 4.64 & 17.01 & $<.001$ \\
Neutral & 6.8 & 2.65 & 2.26 & 1.62 & 5.84 & 33.00 & $<.001$ \\
Thoughtfulness & 1.50 & 1.14 & 3.06 & 2.12 & 0.09 & 33.00 & $n s$ \\
Fear & 1.25 & 0.91 & 1.73 & 1.16 & 1.33 & 25.81 & $n s$ \\
Anger & 1.35 & 0.93 & 1.93 & 1.22 & 1.54 & 25.34 & $n s$ \\
No expression & 3.30 & 2.87 & 1.06 & 0.25 & 2.99 & 19.41 & $<.01$ \\
\hline
\end{tabular}

Note. Expressions were rated on a 7-point scale ranging from 1 (not at all) to 7 (very much). $d f=$ degrees of freedom.

.001), indicating that the list of surprising words was indeed perceived as more unusual than the list of neutral words (surprising: $M=3.05, S D=1.72$; neutral: $M=4.40, S D=.59), t(38)=$ $3.30, p<.005$. The two lists of words did not differ, however, on the positivity-negativity dimension (surprising: $M=2.90, S D=$ 2.51; neutral: $M=4.15, S D=2.06), t(38)=1.71, p>.05$.

\section{Method}

Participants and design. Participants were 50 students of the Warsaw School of Social Psychology, Faculty in Sopot, who received extra course credit for taking part in the study. The study was a 2 (type of facial expression: surprise vs. neutral) $\times 2$ (material to be memorized: surprising vs. neutral) mixed design, with repeated measures on the second factor. Participants were randomly assigned to the facial expression condition and to the order in which they received materials (i.e., whether they saw surprising words first vs. neutral words first). Eight participants were excluded from the study as they had difficulty mimicking the actor's facial expression. Thus, only the data of 42 participants were analyzed.

Procedure and dependent measure. Participants were informed that the study would examine the influence of mimicry on memory abilities. An experimenter who was blind to hypotheses read instructions that informed participants that the experiment would run in two sessions. In the first session, they were told to memorize a list of 20 nouns (surprising or neutral) while adopting and holding the facial expression of a person in a picture. The picture showed the face of a young woman with either a surprised or a neutral facial expression. In the second session, the participants were asked to hold the same expression as they had in the first task, but they were given a counterbalanced word list (i.e., if they had been given the surprised words in the first session, they were then given the neutral word list in the second session, and vice versa). All participants were given 2 min to look at each list of words. Immediately after each session, the participants were asked to recall the material by writing down all the words they remembered. The dependent variable was the number of words remembered correctly. In addition, the experimenter evaluated the accuracy with which participants mimicked the facial expression on a 10-point scale ranging from 1 (hardly accurate) to 10 (perfectly accurate). After participants had written down all the 
words they remembered, they were asked to rate how typical they found the words they were asked to remember on a 9-point scale ranging from -4 (very atypical) to +4 (very typical). Participants also rated their experiential state of feeling surprised from 0 (not at all surprised) to 10 (highly surprised).

\section{Results and Discussion}

All participants felt equally surprised at the end of the procedure $(M$ mimicking surprise $=5.63$ vs. $M$ mimicking neutral face $=$ $5.45, t<1$ ), but rated the neutral list of words as being more typical than the surprising list of words ( $M$ neutral words $=3.00$ vs. $M$ surprising words $=0.44), t(40)=5.62, p<.001$.

We conducted a 2 (type of facial expression) $\times 2$ (learned material) analysis of covariance (ANCOVA) for repeated measures on number of correct words recalled, with the accuracy of mimicking a facial expression included as a covariate. We found a significant main effect of the material that was memorized, indicating that participants recalled more typical words $(M=9.90$, $S D=2.51)$ than atypical ones $(M=8.73, S D=2.82), F(1,39)=$ 9.28, $p<.01, \eta^{2}=.19$. This effect was expected, as typical information is more easily memorized, provided we do not differentiate between reconstructive and generative memory processes (Graesser, 1981). However, we also observed an interaction between the type of facial expression and material that was memorized, $F(1,39)=10.71, p<.01, \eta^{2}=.21$, supporting our hypotheses that participants recalled more words from the list (neutral or surprising) that matched their embodied state (neutral or surprised, respectively). Simple effects contrasts indicate that neutral words were memorized better by participants who were asked to mimic a neutral facial expression $(M=10.40, S D=1.73)$ than those participants who were asked to assume a surprised facial expression $(M=9.35, S D=3.11)$. Conversely, more surprising words were recalled correctly by participants who were asked to mimic a surprised facial expression $(M=9.30, S D=$ 3.46) than those who were asked to mimic a neutral facial expression $(M=8.22, S D=2.04)$. As predicted, if you want to remember things well, your facial expression should match the content of the material.

\section{Study 2}

Study 2 further examined the match between embodied expression and the type of material being memorized. This time, however, rather than manipulating the nature of the content of the stimuli, we manipulated the intonation of the words participants had to recall. Words were either pronounced in a surprising (i.e., with pitch and tempo on last syllable), sad (i.e., with lower pitch and tempo on first syllable), or neutral manner. Also in this study, we strengthened the manipulation of embodiment: Participants had 2 min to hold the facial expression before the procedure and were able to practice the mimic in front of a mirror. Our main prediction was that participants mimicking a surprised facial expression would recall more words that were spoken in a surprising manner than words pronounced in a neutral or sad manner. Conversely, we expected that participants adopting sad facial expressions would recall more words intoned in a sad manner than those intoned in a neutral or surprising manner.

\section{Pilot Test}

A male student at the sound engineering studio at the Technical University of Gdansk recorded a list of 15 five-letter Polish nouns (out of 20 neutral words used in Study 1, e.g., clock, house, door) in a neutral, surprising, and sad manner. The recordings where then cut into single-word segments, controlling for length, volume, and order of appearance. We presented these three recordings to 36 undergraduates. Students were asked to indicate to what extent the words expressed joy, sadness, surprise, disappointment, or neutrality on a scale from 0 (not at all) to 7 (very much). Manipulation of intonation affected participants' judgments: Sad intonation was judged as expressing exclusively sadness $(M=5.88, S D=1.54$; all other emotions were judged significantly lower than this and below the middle of the scale), surprise intonation expressed exclusively surprise $(M=6.83, S D=0.56$; all other emotions judged significantly lower), and neutrally intoned words were judged as only neutral $(M=6.19, S D=1.52$; also all other emotions judged significantly lower).

\section{Method}

Participants and design. Thirty-five students of the Warsaw School of Social Psychology, Faculty in Sopot, volunteered for this study. The study had a 2 (type of facial expression: surprise vs. sad) $\times 3$ (intonation of material to be learned: surprising, neutral, or sad) mixed design, with participants completing all three intonation conditions as a repeated measure. Of the 15 presented words, there were 5 of each type of intonation, which were mixed in random order. Participants were also randomized in terms of mimicry condition.

Materials, procedure, and dependent measure. Each participant was informed that the procedure was a pilot study that would include taking a photograph of their face mimicking a facial expression in free and loaded cognitive states. Participants were told that they were helping to design a future study in which high school students would be presented with a series of faces of people fully concentrating on "making a face" and those who were simultaneously distracted by another task (i.e., memorizing auditory stimuli). Then, using the same facial photographs as in Study 1, we asked half of the participants to mimic a surprised face and half of them to mimic a sad face. After 2 min of practicing the mimicry in front of a mirror, the first photograph of the participant's face was taken. Participants were then instructed to listen to and memorize 15 neutral nouns. During auditory presentation, the second photograph of their face (mimicking a surprised or sad expression) was taken. After hearing the audio stimuli, all participants were then asked to relax their facial muscles and to write down all the words they could recall. All participants were then questioned as to what they believed the study was about and were then debriefed and thanked. Only 1 participant correctly guessed the hypothesis and was removed from the sample; the final sample consequently consisted of 34 students. The dependent variable was the number of words remembered correctly, calculated separately for each different type of intonation. Of the 15 presented words, there were 5 of each type of intonation, resulting in a memory index range from 0 to 5 . 


\section{Results}

Two independent judges blind to the experimental hypotheses were presented with photographs of participants' faces taken during the procedure to assess the level of participants' expression of surprise and sadness. Raters agreed $(r=.80, p<.005)$ that participants in the surprise condition expressed significantly more surprise $(M=4.29, S D=1.86)$ than sadness $(M=.12, S D=.31)$, $t(11.61)=7.63, p<.001$. The opposite was true for students mimicking sad facial expressions (surprise: $M=.45, S D=.49$; sadness: $M=4.50, S D=2.20), t(12.19)=6.19, p<.001$.

A 2 (facial expression: surprise vs. sadness) $\times 3$ (intonation of material: surprising vs. neutral vs. sad) mixed analysis of variance yielded a significant interaction, $F(2,64)=4.09, p<.05, \eta^{2}=.17$, indicating that participants recalled material whose content matched their facial expressions significantly better than they recalled unmatched material. As shown in Figure 1, Study 2 paralleled the results of Study 1, such that participants mimicking the surprised facial expression recalled more words that matched the embodied state (intoned in a surprising manner: $M=2.82, S D=2.34$ ) than the neutral $(M=2.17, S D=1.71), F(1,32)=3.55, p<.05$, or sad states $(M=1.82, S D=1.31), F(1,32)=6.96, p<.01$. In general, words intoned in a surprising manner were recalled better when making a surprised $(M=2.82, S D=2.34)$ rather than a sad facial expression $(M=2.29, S D=1.81), F(1,32)=2.54, p=.06$, whereas sadly intoned words were better recalled when making a sad, rather than a surprised, facial expression (surprised face: $M=1.82, S D=1.31$; sad face: $M=2.70, S D=2.19), F(1,32)=6.22, p<.01$. The number of neutrally intoned words recalled did not differ between conditions $(F<1)$. A main effect of the intonation of words was not significant $(F<1)$, nor was there a sex difference among participants.

\section{General Discussion}

Many years ago, one of the authors was reluctant to obey a primary school rule that forbade students from eating or drinking during class. At this point, we cannot recall what kind of argument stopped this little pupil from sipping his favorite milkshake, but we now agree with all teachers who enforce this rule: Facial expression may be somewhat blocked while chewing gum, eating a snack, or drinking a soft drink, and this lack of congruence with the material being memorized may not be so trivial after all.

The results of the two experiments provide some evidence that matching the facial expression with the material to be learned is beneficial and results in better memory of the material. Study 1 showed that those who were mimicking a surprised versus neutral expression demonstrated better recall for the surprising words, whereas the opposite was true for the neutral words. Study 2 paralleled the results of Study 1, indicating that mimicking a surprising expression facilitated the recall of the words spoken in a surprising manner compared with those that sounded neutral or sad. Conversely, participants who wore a sad facial expression recalled more words that sounded sad than words that sounded either neutral or surprised.

Previous research has discussed embodiment effects mainly in terms of general pleasantness or unpleasantness of the facial expression and material (for review, see Niedenthal et al., 2005). Our studies focused on demonstrating the effects of matching the specific facial expression of surprise with the emotional content of the material to be learned. Despite using the specific facial expressions of anger, fear, and sadness, Laird et al. (1982) did not indicate whether the match between the content and the facial expression is important during the memorization period. Both of our studies suggest that it is.

These studies, however, do not explain the process mediating the observed relationships, and thus they are open to alternative explanations. Laird et al. (1982) concluded that the effects of a content-expression match "are produced by emotional experience, not by the expressions themselves" (p. 655). However, our participants in Study 1 felt equally surprised regardless of their expression, which suggests that emotional experience might not be as

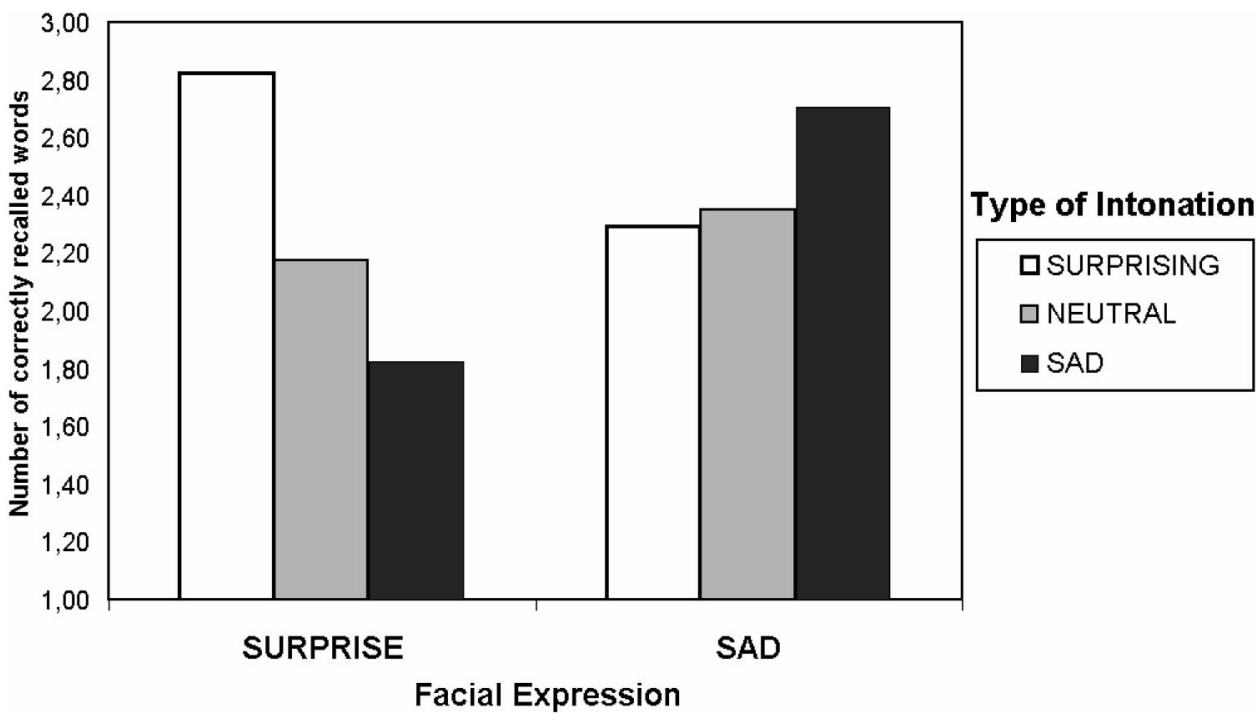

Figure 1. Number of words remembered correctly $(0-5)$ as a function of facial expression and type of intonation. Study 2. 
crucial as supposed. It is important to note that Laird et al. (1982) did not measure what their participants actually felt.

Large, albeit statistically insignificant, mean differences in positivity of the words in Study 1 suggest another alternative explanation: The effects could be driven by the positivity of surprising words. A counterargument to this explanation, however, is that Study 2 showed effects when words did not systematically differ in terms of valence but did differ in ratings of surprise and sadness. This suggests that the effects resulted from the cohesive emotional state rather than positivity or negativity of the stimulus words.

The third possible mechanism is that mimicking a surprised facial expression improves the process of memorizing surprising material via the activation of a "surprise" category. The influence of category activation on information processing has been widely described in the literature and is supported by an abundance of empirical evidence. Many studies have documented that the use of a trait or stereotype influences not only the interpretation of recalled material but also influences attitudes (for reviews, see Anderson, 1983; Bargh, 1994; Collins \& Loftus, 1975; Higgins, 1989; Wyer \& Srull, 1981). However, Strack, Martin, and Stepper (1988) showed that recognizing the emotional expression is not a crucial precondition for the effects of embodiment. Therefore, more research is needed to clarify the interaction between embodied, cognitive, and emotional processes in terms of the link between expression and material.

In sum, these two studies propose that sipping a milkshake during a class at school can be maladaptive for learning new things. While learning new things, you should be able to express the surprise on your face and slap your thighs and say "Wow!" Consider the following example: A teacher gives students an example to help them understand a completely new concept such as the regression toward the mean. The teacher says, "Hey, great news for all ugly newlyweds-your children will probably be less ugly than you are!" Students who do not correctly match their facial expression to the witty remark of the teacher because they are eating, chewing gum, or simply yawning might not remember much about this effect during the next class. Those who are able to laugh and reflect the humor of the material, however, are more likely to recall this valuable lesson and excel on the next statistics exam over their gum-chewing counterparts. Although lighthearted in nature, this specific example reflects what we believe to be a more fundamental concept that should be considered important in the realm of learning in general. As our studies have shown, it is not just what you say, and it is also not just how you say it; it's how well you can see it on your target's face that is critical in the learning of new material.

\section{References}

Anderson, J. R. (1983). A spreading activation theory of memory. Journal of Verbal Learning and Verbal Behavior, 22, 261-295.

Bargh, J. A. (1994). The Four Horsemen of automaticity. In R. S. Wyer \& T. K. Srull (Eds.), Handbook of social cognition (pp. 1-40). Hillsdale, NJ: Erlbaum.

Berkowitz, L., \& Troccoli, B. T. (1990). Feelings, direction of attention, and expressed evaluations of others. Cognition \& Emotion, 4, 305-325.

Bower, G. H. (1981). Emotional mood and memory. American Psychologist, 36, 129-148.
Chandler, J. J., \& Schwarz, N. (2006, May). Feelings at the tips of my fingers: Symbolic body movements influence attitudes. Poster presented at the annual convention of the Association of Psychological Science. New York.

Collins, A. M., \& Loftus, E. F. (1975). A spreading-activation theory of semantic processing. Psychological Review, 82, 407-428.

Förster, J., \& Strack, F. (1997). The influence of motor actions on retrieval of valenced information: A motor congruence effect. Perceptual and Motor Skills, 85, 1419-1427.

Friedman, R. S., \& Förster, J. (2000). The effects of approach and avoidance motor actions on the elements of creative insight. Journal of Personality and Social Psychology, 79, 477-492.

Glenberg, A. M. (1997). What memory is for. Behavioral and Brain Sciences, 20, 1-55.

Graesser, A. C. (1981). Prose comprehension beyond the word. New York: Springer.

Higgins, E. T. (1989). Knowledge accessibility and activation: Subjectivity and suffering from unconscious sources. In J. S. Uleman \& J. A. Bargh (Eds.), Unintended thought (pp. 75-123). New York: Guilford Press.

Kurcz, I., Lewicki, A., Sambor, J., Szafran, K., \& Woronczak, J. (1990). S/lownik frekwencyjny polszczyzny wspó/lczesnej [Frequency dictionary of Polish language]. Kraków: Instytut Języka Polskiego PAN.

Laird, J. D., Wagener, J. J., Halal, M., \& Szegda, M. (1982). Remembering what you feel: Effects of emotion on memory. Journal of Personality and Social Psychology, 42, 646-657.

Neumann, R., \& Strack, F. (2000). "Mood contagion": The automatic transfer of mood between persons. Journal of Personality and Social Psychology, 79, 211-223.

Niedenthal, P. M., Barsalou, L., Winkielman, P., Krauth-Gruber, S., \& Ric, F. (2005). Embodiment in attitudes, social perception, and emotion. Personality and Social Psychology Review, 9, 184-211.

Reed, C. L., \& Farah, M. J. (1995). The psychological reality of the body schema: A test with normal participants. Journal of Experimental Psychology: Human Perception and Performance, 21, 334-343.

Riskind, J. H. (1984). They stoop to conquer: Guiding and self-regulatory functions of physical posture after success and failure. Journal of Personality and Social Psychology, 47, 479-493.

Stepper, S., \& Strack, F. (1993). Proprioceptive determinants of emotional and nonemotional feelings. Journal of Personality and Social Psychology, 64, 211-220.

Strack, F., Martin, L., \& Stepper, S. (1988). Inhibiting and facilitating conditions of the human smile: A nonobtrusive test of the facial feedback hypothesis. Journal of Personality and Social Psychology, 54, 768-777.

Teasdale, J. D., \& Fogarty, S. J. (1979). Differential effects of induced mood on retrieval of pleasant and unpleasant events from episodic memory. Journal of Abnormal Psychology, 88, 248-257.

Wilson, M. (2002). Six views of embodied cognition. Psychonomic Bulletin \& Review, 9, 625-636.

Wyer, R. S., \& Srull, T. K. (1981). Category accessibility: Some theoretical and empirical issues concerning the processing of social stimulus information. In E. T. Higgins \& M. P. Zanna (Eds.), Social cognition: The Ontario Symposium (pp. 161-197). Hillsdale, NJ: Erlbaum.

Zajonc, R. B., Pietromonaco, P., \& Bargh, J. A. (1982). Independence and interaction of affect and cognition. In M. S. Clark \& S. T. Fiske (Eds.), Affect and cognition: The seventeenth annual Carnegie Symposium on Cognition (pp. 211-228). Hillsdale, NJ: Erlbaum.

Received November 14, 2006

Revision received February 2, 2008

Accepted March 14, 2008 